\title{
Chronic ulcerative colitis complicated by atypical carcinoid tumour
}

\author{
SUSAN M DODD
}

From the Department of Morbid Anatomy, King's College School of Medicine and Dentistry, London

SUMMARY A malignant carcinoid tumour of the rectum was found in a patient who had chronic ulcerative colitis. It had a multifocal origin and had not been macroscopically apparent. This association has been recorded in the colon.

Hyperplasia of enterochromaffin cells in ulcerative colitis and also dysplasia of these elements as part of a pancellular dysplasia may occur; and this may be a possible explanation for the development of a carcinoid tumour in this condition.

Crohn and Rosenberg ${ }^{1}$ first described a colonic carcinoma arising in a patient with ulcerative colitis. It is now generally accepted that adenocarcinomas can develop in patients with chronic ulcerative colitis eight to ten times as often as in the general population. ${ }^{2}$ The populations at risk and the pathology of the adenocarcinoma have now been characterised and premalignant lesions defined. ${ }^{3}$ Carcinoid tumours arising in the rectum are uncommon, comprising less than $1 \%$ of tumours in this site, and are usually argentaffin negative; Morson first applied the term "atypical carcinoid".4 Rectal carcinoid arising in ulcerative colitis has not been previously reported, although carcinoid tumours arising in chronic ulcerative colitis are known to occur in the colon. ${ }^{5-7}$

I present a case of a malignant atypical carcinoid and discuss its possible pathogenesis and relation to epithelial dysplasia.

\section{Case report}

A 55 year old man with a 42 year history of ulcerative colitis, had had a total colectomy and ileorectal anastomosis performed in 1948. In 1984 he developed diarrhoea, and investigation showed severe proctitis with perianal fistulae. The rectal stump was removed and an ileostomy was performed. He made a good postoperative recovery and remained well.

\section{Pathology}

A proctocolectomy specimen was received, together with anal skin and a small length of terminal ileum.

Accepted for publication 18 March 1986
The rectal wall was thickened with a granular mucosal surface that showed small areas of ulceration. There was no macroscopic evidence of tumour and no villous areas. Anal skin was unremarkable in appearance, while the small bowel mucosa was congested. The specimen was fixed in formalin and paraffin embedded sections were stained with haematoxylin and eosin with Grimelius and diazo methods applied to selected sections. Multiple sections of rectal stump showed the features of active ulcerative colitis superimposed on chronic colitis with irregularity, branching, and budding of the gland with occasional Paneth cells in the crypts. ${ }^{8}$

Areas of the mucosa showed epithelial dysplasia with changed polarity, multilayering of cells, a high nucleocytoplasmic ratio, and considerable mitotic activity (Fig. 1). These changes were focal and mostly low grade.

Infiltrating the submucosal coat and muscularis propria in a multifocal pattern were groups of cells with round vesicular nuclei showing pleomorphism, conspicuous nucleoli, and scant amounts of cytoplasm with frequent mitoses. The cells often formed islands or ribbon like patterns with some attempt at gland formation but no evidence of mucin production (Fig. 2). Tumour cells could be seen surrounding and infiltrating lymphatics, capillaries, and nerves (Fig. 3). The tumour cells showed a granular positivity with the Grimelius reaction but showed no staining with the diazo technique (Fig. 4). Grimelius stain showed an increase in numbers of argyrophilic cells in the crypts of the damaged mucosa. Small foci of tumour were distributed widely in most of the sections examined, including a site beneath normal anal skin. A zone of high grade pancellular dysplasia overlay a focus of carcinoid tumour. 


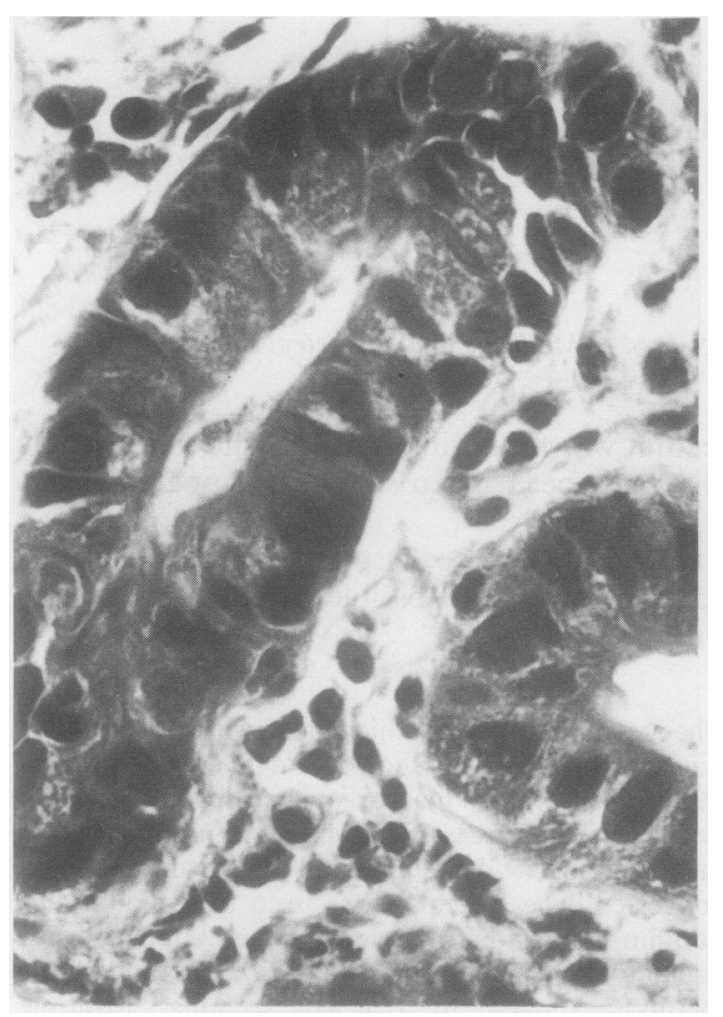

Fig. 1 Dysplasia of mucous membrane. Detail of crypt to show multilayering, loss of polarity, large pleomorphic nuclei, and prominent nucleoli. (Haematoxylin and eosin.) $\times 580$.

Small bowel mucosa above the ileorectal anastomosis showed no abnormality.

Thirteen lymph nodes showed reactive hyperplasia but no evidence of metastatic tumour.

\section{Discussion}

The tumour occurred in a patient with chronic ulcerative colitis; it had a multifocal origin, although it was not apparent macroscopically. The mucosa from which it arose was not polypoid or villous but showed high grade dysplasia. The previous cases of carcinoid tumour arising in ulcerative colitis had been seen in the colon, had presented as abdominal pain or obstruction, and had been described as either annular, ${ }^{5}$ fungating, ${ }^{6}$ or ulcerated tumours. ${ }^{7}$

Carcinoid tumours are derived from amine precursor uptake and decarboxylation cells (APUD). In 1969 Pearse $^{9}$ suggested that these cells might have had a common embryologic origin in the neural crest. In a light and electron microscopic study Sidhu ${ }^{10}$ sug-

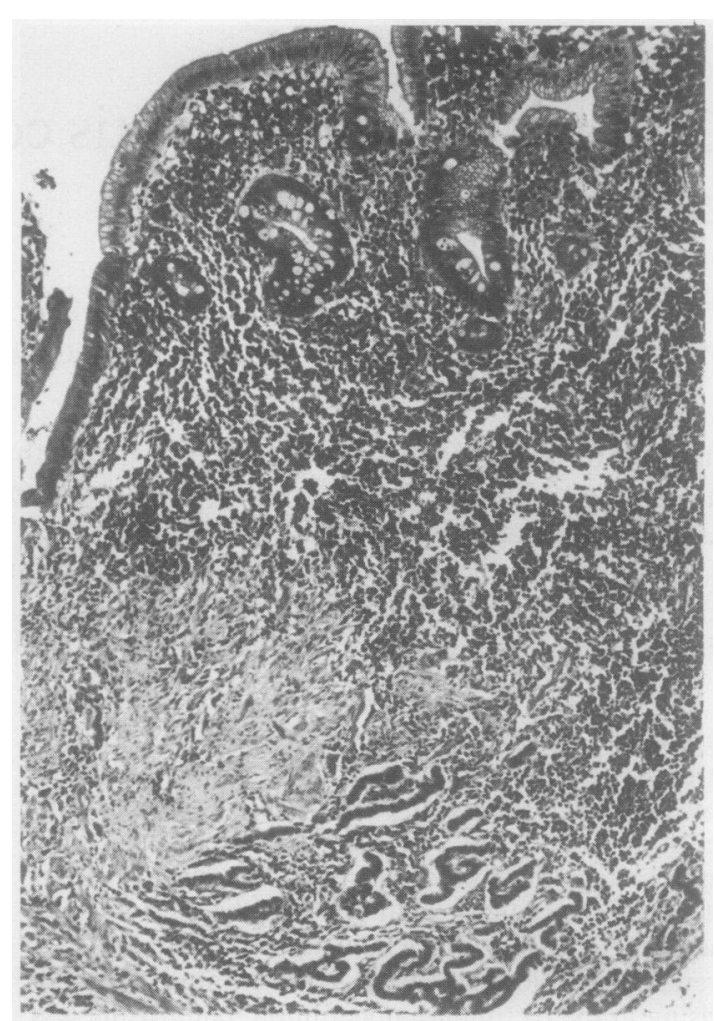

Fig. 2 Carcinoid tumour arising in submucosa of large bowel wall showing features of chronic colitis. Tumour is present in ribbons and cords. (Haematoxylin and eosin.) $\times 120$.

gested an endodermal origin for digestive and respiratory tract APUD cells and this is now generally accepted.

There are two hypotheses regarding the development of carcinoid tumours ${ }^{11}$; they may arise as a consequence of neoplastic transformation of endocrine cells ${ }^{12}$; or they may be derived from primitive endodermal cells capable of differentiating into any mature intestinal cell type. The second view is supported by studies of normal intestinal cytodifferentiation, ${ }^{13}$ and by experiments entailing cloning of cells from experimental colonic carcinomas. ${ }^{14}$

Rectal carcinoid tumours comprise only $9 \%$ of gastrointestinal carcinoids ${ }^{15}$ and are classified into three main varieties: "true" carcinoid or argentaffinoma; "atypical" or non-argentaffin carcinoid; and the composite carcinoid showing mucin positivity. Most are of the atypical type (non-argentaffin) and benign. ${ }^{416}$

Patients with ulcerative colitis have an increased risk of developing carcinoma of the colon. De Dombal et $a l^{17}$ showed that the risk is greatest in 


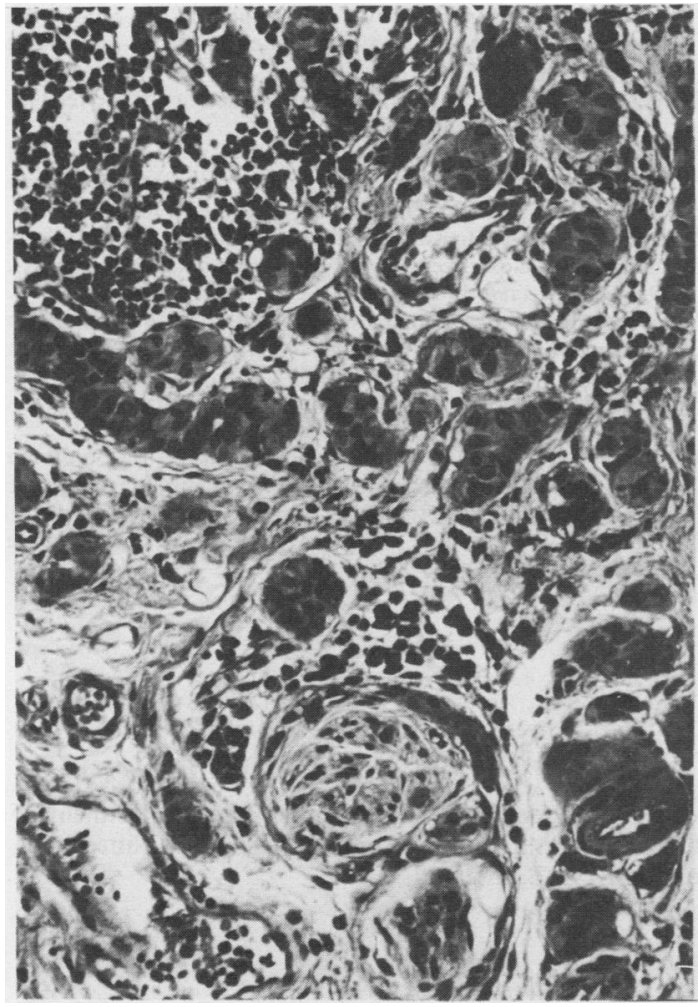

Fig. 3 Carcinoid tumour in submucosa showing infiltration of capillaries, lymphoid follicles, and nerves. (Haematoxylin and eosin.) $\times 300$.

those with total colitis and that those with only distal disease are at low risk of developing carcinoma. If the disease starts before the age of 25 years the risk is also greater, ${ }^{18}$ and this may be preceded by and is often accompanied by dysplasia, described by Riddell ${ }^{19}$ in a study of 111 cases of carcinoma in chronic colitis and divided into five groups: adenomatous change; basal cell proliferation; in situ anaplasia; clear cell change; pancellular dysplasia.

These five patterns seemed to be closely related to carcinoma, and the first two were found to be relatively common while the three others were comparatively rare. Pancellular dysplasia is associated with dysplasia of epithelial, goblet, Paneth, and argentaffin cell lines, manifest as large hyperchromatic nuclei and loss of polarity; and it occurs in flat featureless mucosa. This type most closely fits the changes seen in this case.

Studies of argentaffin cell populations in ulcerative colitis have been carried out, although the results have been different. Watson and Roy ${ }^{20}$ found an increase in numbers of argentaffin cells using the diazo technique. Verity et al, ${ }^{21}$ using the same tech-

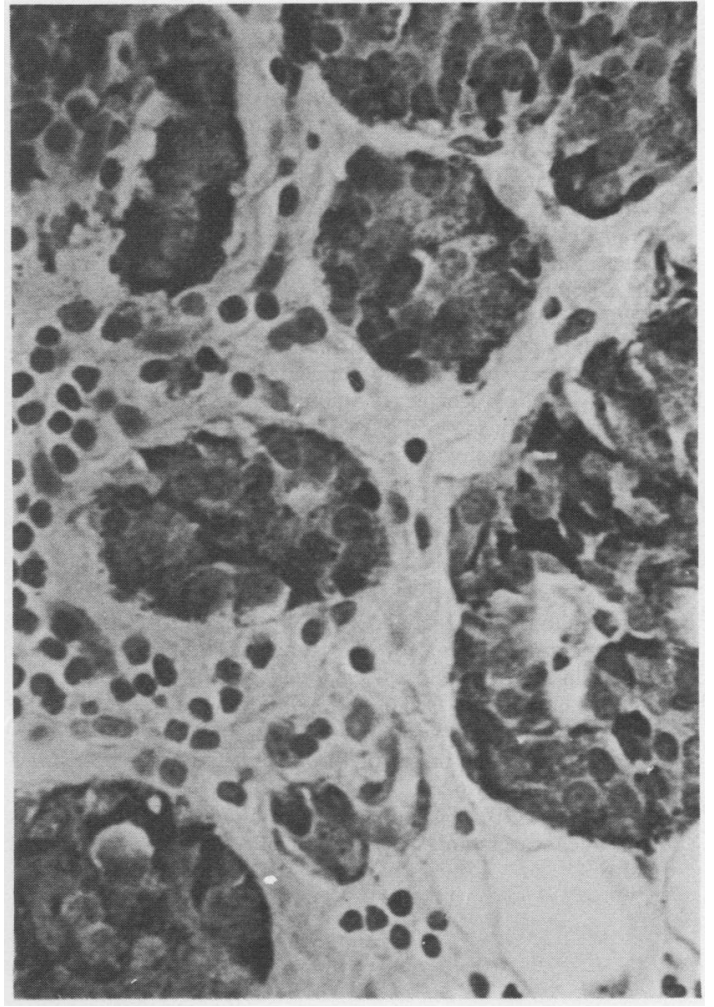

Fig. 4 Granular positivity of tumour cells. (Grimelius.) $\times 580$.

nique, found a decrease proportional to the severity of mucosal damage. Skinner et $\mathrm{ll}^{22}$ used the Fontana stain and found a decrease in the number of argentaffin cells, which was not proportional to the severity or duration of the disease. Techniques for argyrophilia, however, were not used in these studies. Miller and Sumner ${ }^{7}$ described argyrophilic cell hyperplasia in chronic ulcerative colitis as a reaction to injury and this agreed with our findings.

It would seem likely, therefore that in this "high risk" patient, with a long history of ulcerative colitis and early disease onset, repeated mucosal damage led to pancellular dysplasia in which the argyrophilic cell line became overtly neoplastic.

I thank $\mathrm{Mr} \mathrm{H}$ Berry for permission to publish the clinical details of this patient.

\section{References}

${ }^{1}$ Crohn BB, Rosenberg H. The sigmoidoscopic picture of chronic ulcerative colitis (non-specific). Am J Med Sci 1925;170:220-8.

${ }^{2}$ Morgan CN. Malignancy in inflammatory diseases of the intestines. Cancer 1971;28:41-4. 
${ }^{3}$ Morson BC, Pang L. Rectal biopsy as an aid to cancer control in ulcerative colitis. Gut 1967;8:423-4.

${ }^{4}$ Morson BC. In: Avery Jones F, ed. Modern trends in gastroenterology 2nd series. London: Butterworths, 1958:107-8.

${ }^{5}$ Hay DJ, Curt JRN. Carcinoid tumour as a complication of ulcerative colitis. Postgrad Med J 1979;55:430-2.

${ }^{6}$ Owen DA, Hwang WS, Thorlakson RH, Walli E. Malignant carcinoid tumour complicating chronic ulcerative colitis. Am J Clin Pathol 1981;76:333-8.

${ }^{7}$ Miller RR, Sumner HW. Argyrophilic cell hyperplasia and an atypical carcinoid tumour in chronic ulcerative colitis. Cancer 1982;50:2920-5.

${ }^{8}$ Morson BC, Dawson IMP. Gastrointestinal pathology. 2nd ed. London: Blackwell Scientific Publications, 1979:531-9.

${ }^{9}$ Pearse AGE. The cytochemistry and ultrastructure of polypeptidehormone producing cells of the APUD series and the embryologic, physiologic and pathologic implications of the concept. J Histochem Cytochem 1969;17:303-13.

${ }^{10}$ Sidhu GS. The endodermal origin of digestive and respiratory tract APUD cells. Am J Pathol 1979;96:5-20.

${ }^{11}$ Bensch KG. The problem of classifying peripheral endocrine tumours. Hum Pathol 1983;14:383-5.

${ }^{12}$ Rode J, Dhillon AP, Papadak I, Griffiths D. Neurosecretory cells of the lamina propria of the appendix and their possible relationship to carcinoids. Histopathology 1982;6:69-79.

${ }^{13}$ Cheng $\mathrm{H}$, Leblond $\mathrm{CP}$. Origin, differentiation and renewal of the 4 main epithelial cell types in the mouse small intestine. V. Unitarian theory of the origin of the 4 epithelial cell types. Am J Anat 1974;141:537-62.

${ }^{14}$ Cox WF, Pierce GB. The endodermal origin of the endocrine cells of an adenocarcinoma of the colon of a rat. Cancer 1982;50: 1530-8.
${ }^{15}$ Olney JR, Urdaneta LF, Al-Jurf AS, Jochimsen PR, Shirazi SS. Carcinoid tumours of the gastrointestinal tract. American Surgeon 1985;51:37-41.

${ }^{16} \mathrm{Gibbs}$ NM. The histogenesis of carcinoid tumours of the rectum. J Clin Pathol 1963;16:206-4.

${ }^{17}$ De Dombal FT, Watts J McK, Watkinson G, Goligher JC. Local complications of ulcerative colitis, sticture, pseudopolyposis and carcinoma of the colon and rectum. Br Med J 1966;i:1442-7.

${ }^{18}$ Macdougall IPM. Clinical identification of those cases of ulcerative colitis most likely to develop carcinoma of the bowel. Dis Colon Rectum 1964;7:447-50.

${ }^{19}$ Riddell RH. The precarcinomatous phase of ulcerative colitis. In: Morson BC, ed. Current topics in pathology. Vol 63. New York Springer-Verlag, 1976:179-219.

${ }^{20}$ Watson AJ, Roy AD. Paneth cells in the large intestine in ulcerative colitis. J Pathol Bacteriol 1960;80:309-23.

${ }^{21}$ Verity MA, Melinkoff SM, Frankland M, Greipel M. Serotonin content and argentaffin and Paneth cell changes in ulcerative colitis. Gastroenterology 1962;43:24-31.

${ }^{22}$ Skinner JM, Whitehead R, Piris J. Argentaffin cells in ulcerative $\infty$ colitis. Gut 1971;12:636-8.

Requests for reprints to: Dr Susan Dodd, Department of Morbid Anatomy, The London Hospital, Whitechapel, London E1 1BB, England. 